\title{
Investigation of ecogeophysical factors of the environment of Vladikavkaz
}

\author{
Vladislav Zaalishvili1 ${ }^{1,2}$, Olga Burdzieva $^{2}$, Tamaz Zaks², and Aleksandr Kanukov \\ ${ }^{1}$ North Ossetian State University after K.L. Khetagurov, 362025, Vatutina Street, 44-46, Vladikavkaz, \\ North Ossetia - Alania, Russian Federation \\ ${ }^{2}$ Geophysical Institute, Vladikavkaz Scientific Center, Russian Academy of Sciences, 362002, \\ Markova Street, 93a, Vladikavkaz, Russian Federation
}

\begin{abstract}
A study of ecogeophysical factors of the environment in Vladikavkaz was carried out at 126 points: indicators of noise pollution, electric fields and the level of gamma radiation were measured. The noise level was determined with the help of noise and vibration meter Ekogeofizika-110A of the domestic company Oktava. It has been defined that the population of Vladikavkaz is subjected to a significant noise period of time, which exceeds the permissible level, which can negatively affect the health of citizens. Measurements of gamma radiation level were made using a gamma radiation dosimeter DBGA-OCHA. According to the obtained data, the population of Vladikavkaz is exposed to the gamma radiation in the range of $0.05-0.18 \mathrm{~Sv} / \mathrm{h}$ and with an average value of $0.11 \mathrm{~Sv} / \mathrm{h}$, which is below the maximum permissible level. In order to study the electric fields, the measurements were carried out by the electric field meter IEP-05. The electric field strength reached up to $1400 \mathrm{~V} / \mathrm{m}$ at individual measurement points, at an acceptable level of $800 \mathrm{~V} / \mathrm{m}$; this indicator exceeds the maximum permissible values.
\end{abstract}

\section{Introduction}

Environmental protection has become a global problem due to the growing anthropogenic impact. It should be noted that almost all types of natural phenomena and processes of a geological, hydrogeological and meteorological nature are considered as the risk sources [1].

Noise pollution is one of three most significant environmental disruptions in the world. Noise has become a constant part of human life and one of the significant parametric pollutants of the urban environment with the growth of urbanization. The problem of population protection from excessive noise is, first of all, the problem of health maintenance. Acoustic pollution in the world is about $70-75 \%$ of all environmental pollution. Noise pollution leads to the increased fatigability of humans and animals, to the decrease in labor productivity and physical and nervous diseases.

Increased noise affects the nervous and cardiovascular systems, causes irritation, fatigability, aggressiveness etc. Tens of millions of workers and hundreds of millions of

* Corresponding author: cgi ras@mail.ru 
urban residents are under the influence of increased noise all over the world. This is a medical aspect of the noise effect on humans.

Noise also affects labor productivity. At noise levels above $80 \mathrm{dBA}$, every 1-2 dBA increase will cause a decrease in labor productivity by at least $1 \%$. Economic losses caused by the increased noise level in the developed countries reach tens of billions of dollars per year. Today, the competitiveness of machines is largely determined by their noise level. The less noise of the machine, unit, installation, the more expensive it is. Any $1 \mathrm{dBA}$ of noise reduction provides near $1 \%$ increase in the value of the product. The cost of noise protection in modern aircraft reaches $25 \%$ of the cost of the product, and in cars it reaches $10 \%$.

Despite the costs of anti-noise measures in the countries of the European Union, about 130 million people are e subjected to a noise influence, which causes anxiety and irritation, exceeding the permissible limits. Thus, the costs of anti-noise measures are insufficient and, according to the experts, should be 2-3 times higher.

One of the main environmental problems in cities is noise pollution from automobile transport; it largely determines the quality of the population life [2]. Design and construction of residential buildings in the vicinity of industrial buildings takes place in accordance with technical standards for the operation of buildings and structures. Therefore, sounds striking residents of nearby houses and people who are close are not dangerous to their health. Satisfactory situation allows them to relax and sleep relatively peacefully. And the installation of soundproof double-glazed windows protects more effectively against the sounds from outside. Noise pollution is estimated by the following parameters: sound level, volume, vibration and sound pressure [3].

A noise of 20-30 dB is practically harmless to humans and constitutes a natural sound background, the life without which is impossible. As for the "loud sounds", here the permissible limit rises to about $80 \mathrm{~dB}$. A noise of $130 \mathrm{~dB}$ already causes a pain to a person, and noise reaching $150 \mathrm{~dB}$ becomes intolerable for him. This explains why in the Middle Ages there was a death sentence "under the bell". In the old days, one of the most barbaric methods of execution that a person could have invented by that time. It looked something like this: the death row was put under a huge, low-hanging bell was swinging overhead. The unfortunate one was dying slowly, in terrible agony. Then, of course, no one had a clue about any decibels. But the result of a long exposure to noise on a living organism was known, of course, long before the birth of the great Alexander Graham Bell, for which, in fact, the unit of sound measure was named.

If in the 60-70th years of the last century the noise in the streets did not exceed $80 \mathrm{~dB}$, today it reaches $100 \mathrm{~dB}$ or more. On many busy highways, even at night, the noise is not lower than $70 \mathrm{~dB}$, while according to sanitary standards it should not exceed $40 \mathrm{~dB}$.

The continuing increase of the intensity of traffic and the associated increase of traffic noise lead to a constant increase in noise load on the population living in areas adjacent to roads. Protection from traffic noise in the areas adjacent to highways consists in their functional zoning, taking into account permissible sound levels during day or night, and also in the use of passive and active measures to reduce traffic noise.

\section{Methods}

To conduct monitoring of ecogeophysical factors of the environment in Vladikavkaz, we measured the noise pollution indicators, the level of gamma and electromagnetic radiation at 126 points in the city [4]. The noise level was measured using a noise and vibration meter Ekogeofizika-110A of the domestic company Octava. Higher noise levels were noted on the main streets and their intersections. The scatter of indicators ranged from 53 to 105 dB (Fig. 1-2). 


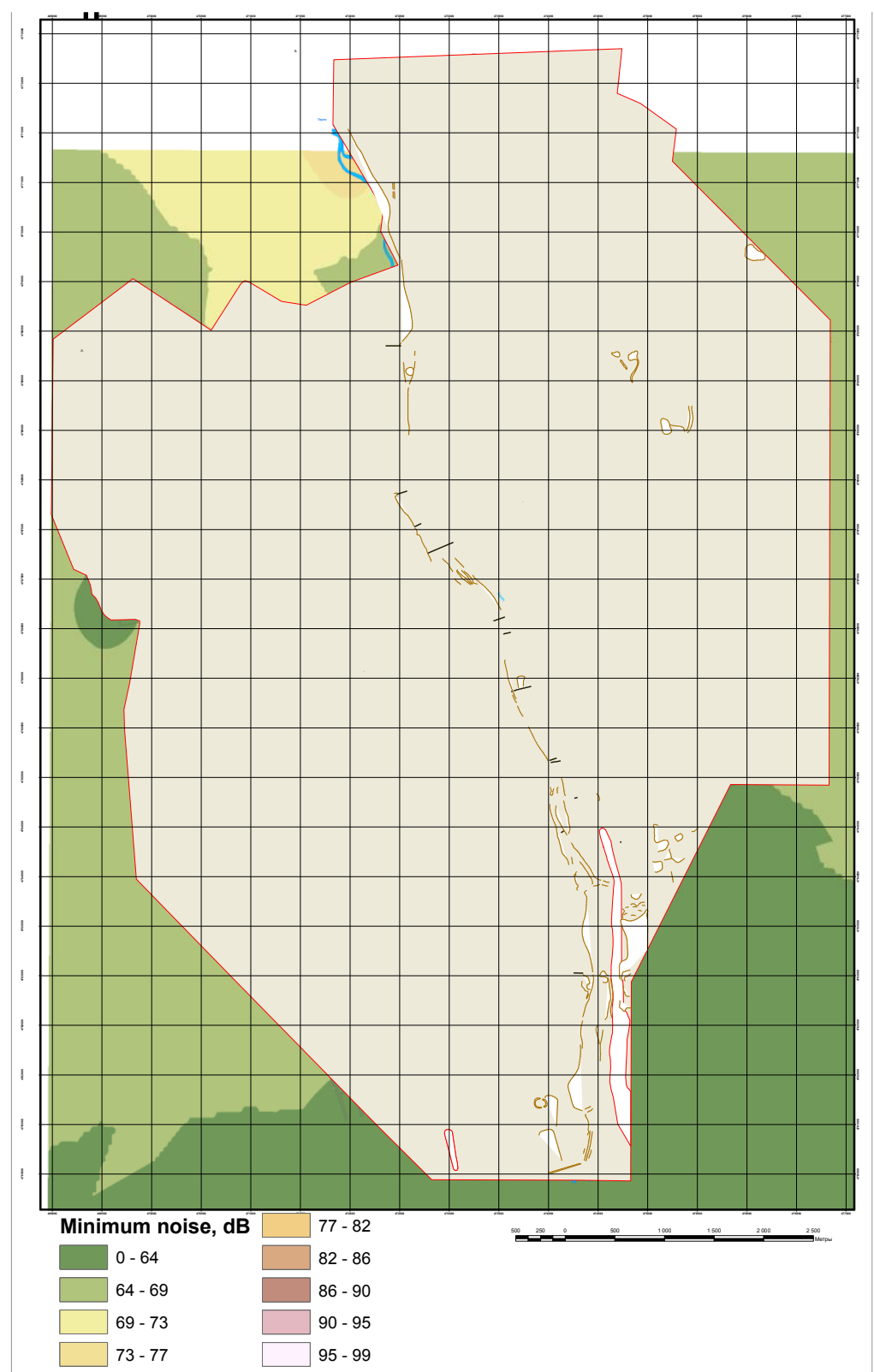

Fig. 1. Distribution of the minimum recorded noise level (dBA) in Vladikavkaz. 


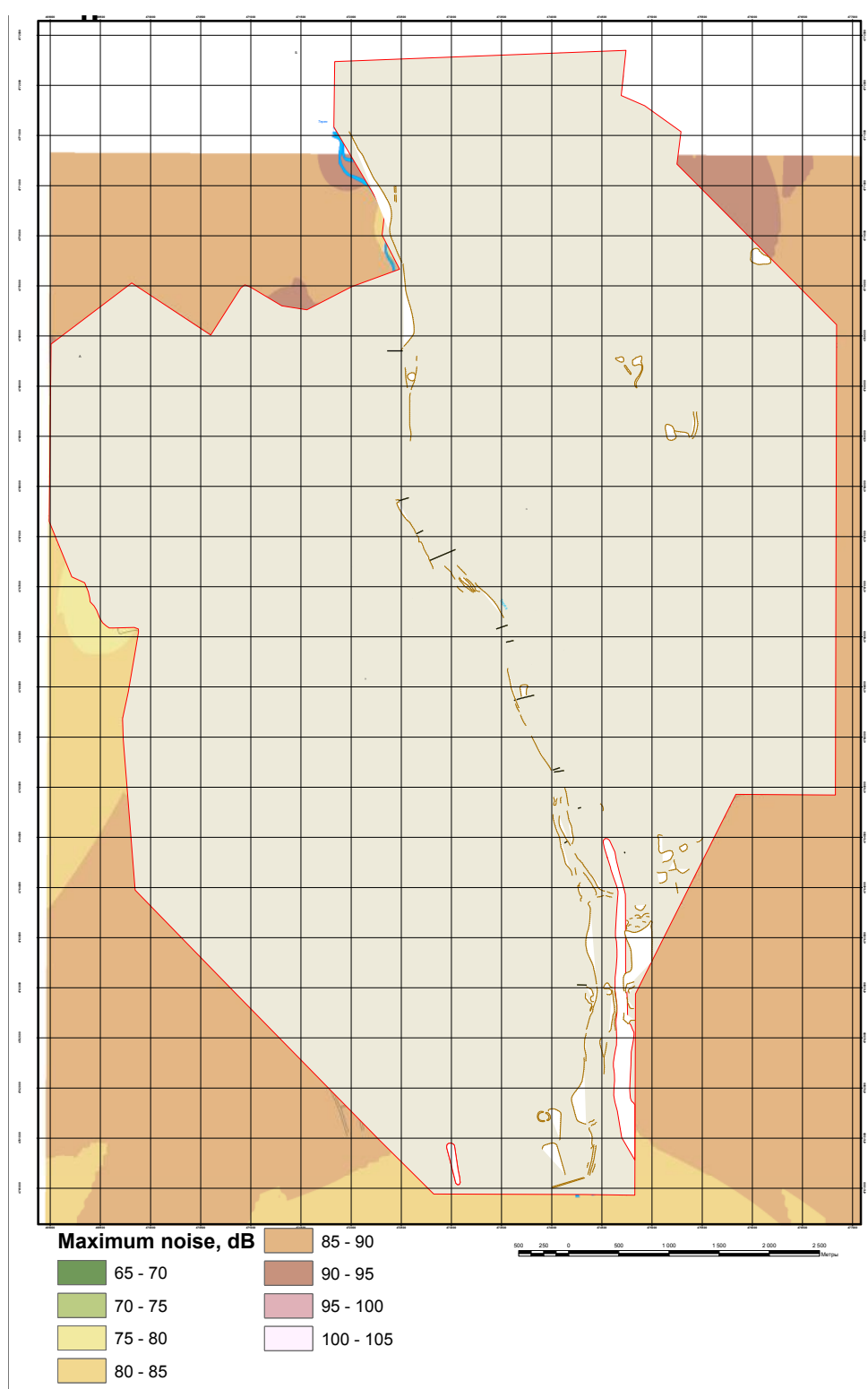

Fig. 2. Distribution of the maximum recorded noise level (dBA) in the territory of Vladikavkaz.

Measurements of gamma radiation level were also made in 126 points of the city with the help of the gamma radiation dosimeter DBGA-OCHA. The indicators varied from $0.05-0.18 \mu \mathrm{Sv} / \mathrm{h}$ with acceptable values of $0.33 \mu \mathrm{Sv} / \mathrm{h}$ (Fig. 3).

To study the electric fields, the measurements were carried out by the electric field meter IEP-05. The electric field parameters were up to $1400 \mathrm{~V} / \mathrm{m}$ at individual measurement points with an acceptable level of $800 \mathrm{~V} / \mathrm{m}$ (Fig. 4). 


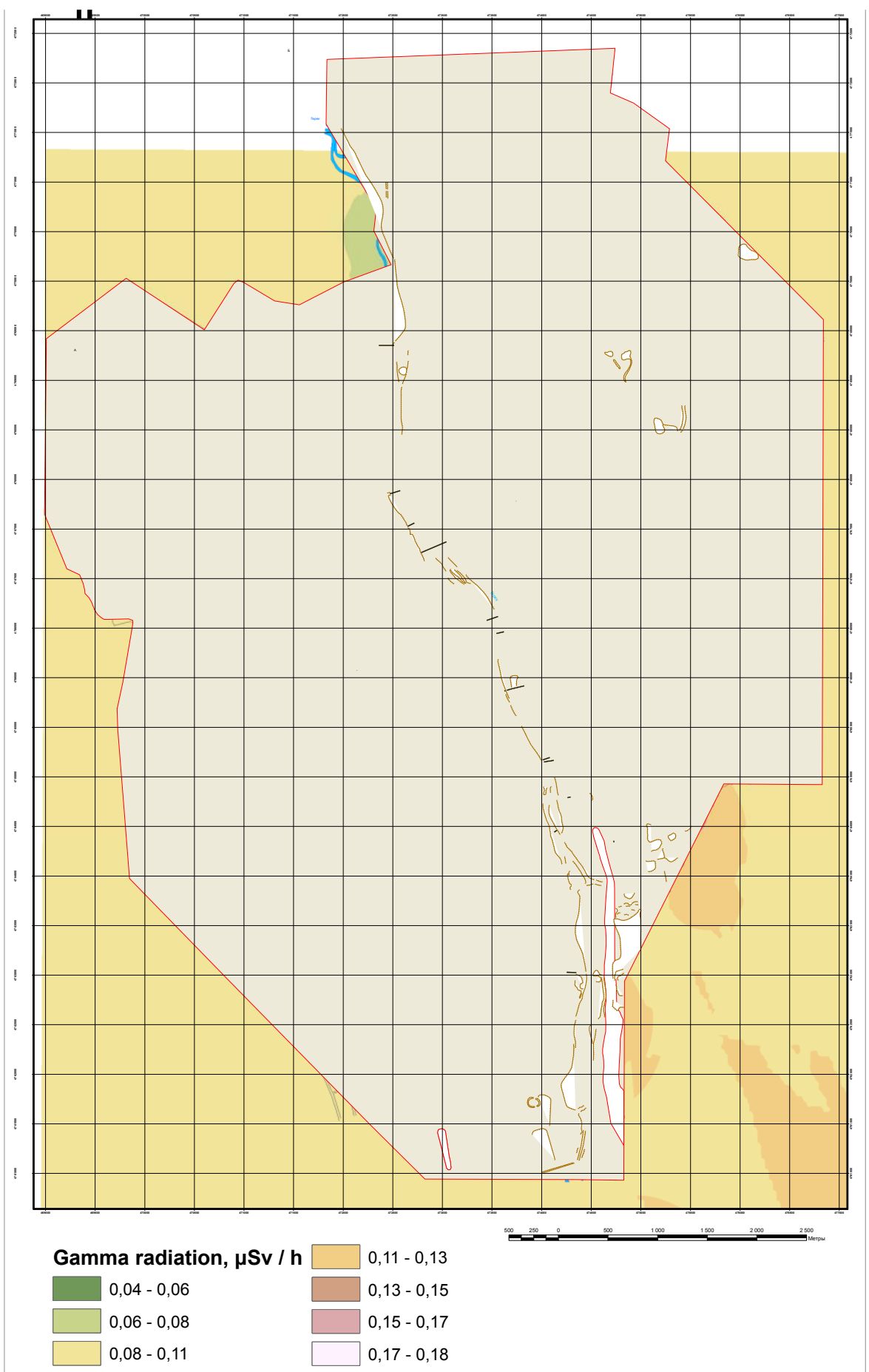

Fig. 3. Distribution of gamma radiation level ( $\mathrm{Sv} / \mathrm{h}$ ) registered in Vladikavkaz. 


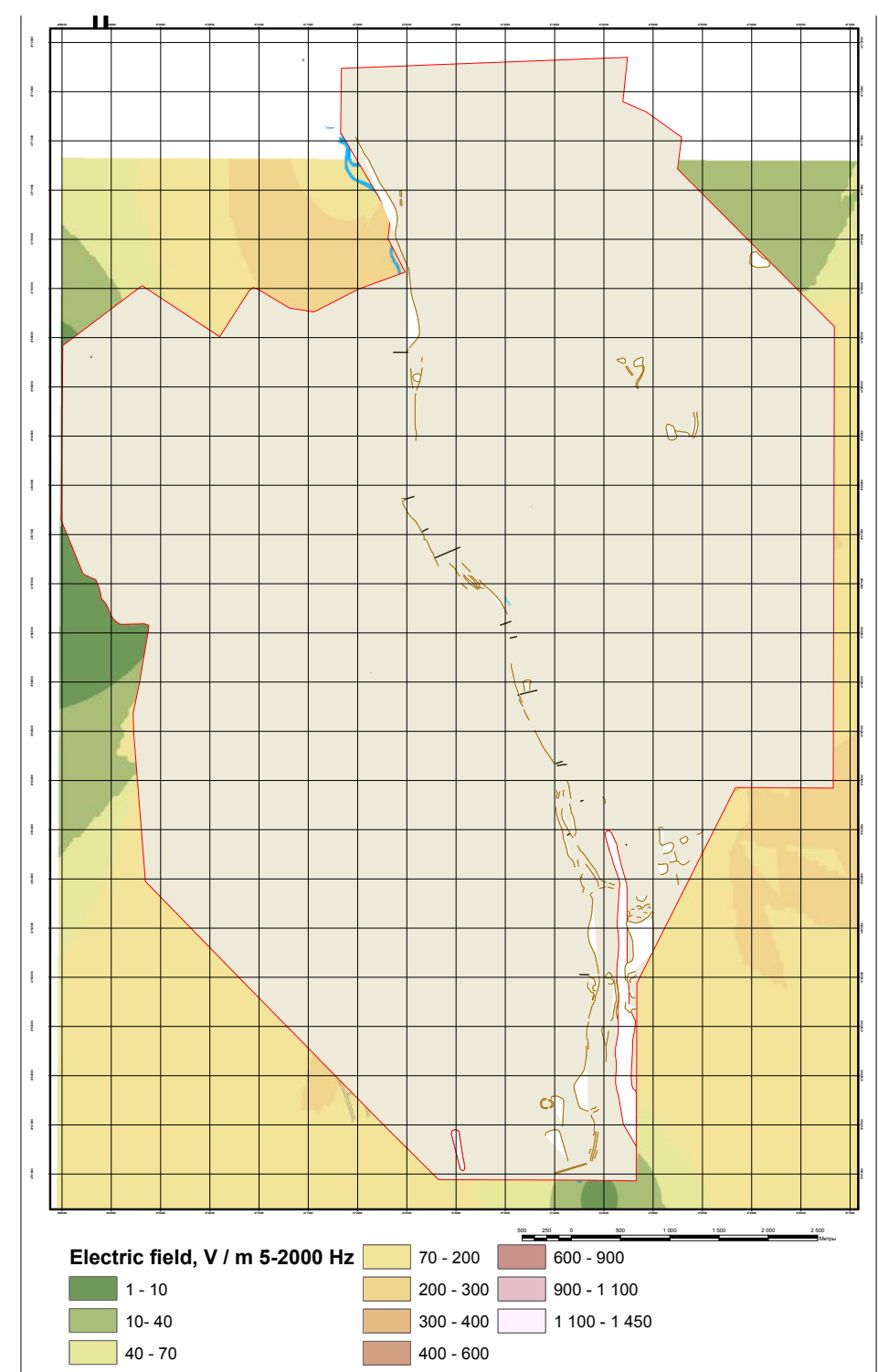

Fig. 4. Distribution of the electric field level $(\mathrm{V} / \mathrm{m})$ registered in Vladikavkaz.

\section{Results}

Monitoring of ecogeophysical factors of the environment of Vladikavkaz was carried out: indicators of noise pollution, electric fields and the level of gamma radiation were measured.

According to the observation results, certain orders and patterns of the changes in structure of car and lorry traffic along the main routes in Vladikavkaz (the Republic of North Ossetia-Alania) at different periods of the day are revealed. This data provides the basis for the analysis and development of the appropriate mathematical models, as well as the forecast of ecological well-being in the area of the increased noise risk. In general, the population of Vladikavkaz continues to be exposed to noise influence [5] for a considerable 
time period. This influence exceeds the permissible level, which can negatively affect the health of citizens.

It should be noted that the previous studies of electric fields showed that their indexes do not exceed the maximum permissible levels [6], which indicates an increase in the electric field within the city.

The population of Vladikavkaz is exposed for a significant period of time to the noise influence, which exceeds the permissible level from 1 to $38 \mathrm{dBA}$.

According to the obtained data, it can be concluded that the population of Vladikavkaz is exposed to gamma radiation in the range of $0.05-0.18 \mu \mathrm{Sv} / \mathrm{h}$ and with an average value of $0.11 \mu \mathrm{Sv} / \mathrm{h}$, which is below the maximum permissible level. The electric field strength reached up to $1400 \mathrm{~V} / \mathrm{m}$ at individual measurement points, at an acceptable level of 800 $\mathrm{V} / \mathrm{m}$, exceeding the maximum permissible values. At the same time, it should be noted that compared to the other sites there is a significant increase in these indicators on the outskirts of the city, at the points adjacent to power lines, as well as within the city on the streets with tram traffic.

\section{Discussion of results}

Thus, the obtained results and the available literature data suggest that ecogeophysical environmental factors can negatively affect the morbidity rate of the population of Vladikavkaz.

The results of the study of ecogeophysical factors influence on the population health of Vladikavkaz show that in the different parts of the city the population is affected by negative environmental factors to varying degrees, and the growths of neoplasms, congenital anomalies, blood and blood-forming organs, different organs and systems of the human body are noted among the morbidity indicators.

In order to draw more reliable inference and conclusions, it is necessary to conduct a special comprehensive study with a more detailed and more in-depth (at least 5 years) study of the health indicators of the adult and children's population, as well as an increase in the number of research points and the number of studies of ecogeophysical environmental factors. Based on the obtained data, using the method of medical-ecogeophysical zoning, it will be possible to define how environmental factors affect the population health.

\section{References}

1. P. Kardol, C. Spitzer, M. Gundale, M. Nilsson, D. Wardle, Ecology Letters 19, 967976 (2016) doi: 10.1111/ele.12635

2. E. Perkins, G. Ankley, K. Crofton, et al., Environmental Health Perspectives 121 (9), 1002-1010 (2013) doi: 10.1289/ehp.1306638

3. T. Zaks, A. Kanukov, I. Maliev, et al., Geology and Geophysics of Russian South 4, 68-74 (2016) doi: 10.23671/VNC.2016.4.20900

4. I. Alborov, O. Burdzieva, F. Tedeeva, et al., Advances in Engineering Research 182, 18 (2019) doi: 10.2991/ciggg-18.2019.1

5. C. Stechow, D. McCollum, K. Riahi, Annual Review of Environment and Resources 40, 363-394 (2015) doi: 10.1146/annurev-environ-021113-095626

6. O. Burdzieva, V. Zaalishvili, et al., Advances in Engineering Research 182, 50-56 (2019) doi: 10.2991/ciggg-18.2019.10

7. L. Eisen, R. Eisen, Annual Review of Entomology 56, 41-61 (2011) doi: 10.1146/annurev-ento-120709-144847 
8. R. Hobbs, V. Cramer, Annual Review of Environment and Resources 33, 39-61 (2008) doi:10.1146/annurev.environ.33.020107.113631

9. O. Burdzieva, V. Zaalishvili, et al., International Journal of GEOMATE 10-1, 16931697 (2016) doi: 10.21660/2016.19.5327

10. V. Golik, O. Burdzieva, V. Zaalishvili, et al., Advances in Engineering Research, 111119 (2019) doi: 10.2991/ciggg-18.2019.21

11. O. Beriev, T. Zaks, A. Kanukov, Geology and Geophysics of Russian South 3, 27-39 (2017) doi: 10.23671/VNC.2017.3.9503

12. G. Houtven, J. Pphelan, et al., Ecological Monographs 89 (2), e01345 (2019) doi: 10.1002/ecm. 1345

13. T. Zaks, A. Kanukov, et al., Geology and Geophysics of Russian South 4, 68-74 (2016) doi: 10.23671/VNC.2016.4.20900

14. J. Patz, D. Campbell-Lendrum, T. Holloway, J. Foley, Nature 438, 310-317 (2005) doi: 10.1038/nature04188

15. Kh. Chotchaev, V. Zaalishvili, et al., Advances in Engineering Research, 68-77 (2019) doi: 10.2991/ciggg-18.2019.13

16. H. Byerly, A. Balmford, et al., Frontiers in Ecology and Environment 16 (3), 159-168 (2018) doi:10.1002/fee.1777

17. J. M. Ferguson, B. Reichert, R. Fletcher Jr., H. Jager, Ecology 98 (11), 2813-282 (2017) doi:10.1002/ecy.1966

18. S. Clayton, C. Litchfield, S. Geller, Frontiers in ecology and environment 11 (7), 377382 (2013) doi:10.1890/120351 